\title{
Writing and Speaking in Medicine
}

\section{How I read}

\author{
J W HOWIE
}

British Medical fournal, 1976, 3, 1113-1125

\section{Summary \\ Not all who look at a journal are going to read even one of the articles in it. Writers must know, therefore, what turns a looker into a reader.}

\section{Importance of title}

Unless the title interests me, I go no further. The content must be clearly indicated, but the form of the words is also important. A highly unappealing title is any one which has the weak schoolboy-essay form: "The (whatever it is) followed by of"for example, "The incidence and sources of salmonellas in chickens" will not attract readers, who might respond to "How chickens acquire salmonellas." The short title with an active, brisk flavour and a clear indication of what is in the article makes a good start to winning a reader.

The names and addresses of the authors also matter. Wellknown authorities writing from departments of good repute enjoy an advantage-grossly unfair, of course-over unknowns. Journals which do not give the authors' names and qualifications, the titles of their papers, and their posts in an obvious placethat is, on the front or back cover page-do their contributors a poor service. With so many journals to be looked at in order to keep up to date, the busy reader is very apt to skip those which hide their contents page among advertisements.

\section{Need for an informative summary}

After the title, I look at the summary; so the best place

Newtonmore, Inverness-shire

J W HOWIE, MD, FRCPATH (retired) (Formerly a microbiologist) for this is just after the title and authors' names. If the summary is informative, I am encouraged. If it is merely indicative, I am discouraged. An example of an indicative, weak summary would be something of this sort: "An extensive survey of chickens in various situations has been made to ascertain the incidence and points of origin of salmonellas. The results show where infection has been acquired and point to the need for further research." This will deter any but the toughest readers. Waverers might be won by something stronger like this:

"Five thousand chickens were examined for salmonellas in 20 farms, three processing plants, and 100 shops. Infected feed containing fish meal on one farm was found to result in widespread contamination of birds from that farm and through them of clean birds as they passed through one processing plant. We conclude that efforts to produce clean poultry feed and to improve the hygiene of farms and processing plants will do more to control food poisoning than the numerous, currently popular but futile searches for human so-called carriers in shops, restaurants, and homes."

This essentially informative and controversial statement of conclusions will compel me to read further to see if the prima facie evidence is good enough. If it is, the case for further research along these lines needs neither argument nor statement.

\section{Where is the evidence?}

If the author and editor have done well by the reader, there will be an easily found section containing all the results and observations. Here there will be tables, graphs, histograms, or illustrations with just enough supporting text to guide the reader through the evidence from beginning to end; and there will be a statistical evaluation where this is necessary and relevant. There is no need to present the same evidence in graphic and in tabular form. The need is to choose which form most clearly and accurately gives the facts to the reader.

The evidence section is the real heart of any good scientific paper, and it is what the author should first assemble if he shares my view of what he is doing for his reader. If it satisfies his 
own critical judgment he should then write the informative summary in order to focus his mind on the essentials of his message. He will thus discover if he has indeed a worthwhile message to deliver and he will have given himself a clear picture of what is relevant and what is merely incidental to its presentation.

\section{What is next?}

If the evidence is good and the results are interesting, I next wish to know what the authors make of them. Where do they take us? So I turn to the discussion and, if it is convincing I shall next look at the introduction and review of previously published papers on the same subject. Involved discussions of a quasi-philosophical, theological, mystical, or autobiographical nature are not welcome. The discussion needs life and colour. A bit of controversy is good for interest, but it must not be manufactured or forced. It can readily be carried too far; and personality conflicts are out of place. A good discussion will make me read the introduction and review of the literature to see why the work was undertaken and if the paper is really advancing knowledge and understanding. Long preambles are not needed to justify undertaking a piece of investigation, and exhaustive bibliographies are exhausting. Authors have a duty to read other workers' papers and to study them exhaustively but they do not need to prove the extent of their virtue to ordinary readers of journals. Admittedly the matter is different if the reader is the examiner of a thesis; but this is not what we are considering here.

\section{How I subedit}

\section{W F WHIMSTER}

Articles pour into the medical journal offices. The editors try to judge them on their scientific value, but their task is difficult, since in very few does the scientific value shine out completely clearly. The language of most articles makes very hard reading - which does not endear them to the editors. Preparing the accepted articles for the printers is hard work too; that is the job of the subeditor, be he employed by the journal or freelance, professional or amateur.

As a freelance subeditor or language supervisor, mainly for articles written by authors whose native language is not English, I have tried to identify the criteria I use to improve clarity. In fact, I find that I am looking to see whether the authors have applied the advice given by the other contributors to this symposium.

I start by cutting away the verbiage until I can answer "Why did he start?" in the introduction (easily the worst done section); "What did he do?" in the methods section; "What did he find?" among the results; and "What does it mean ?" in the discussion. Journal club members have many good opportunities to practise this-and will find themselves rejecting from their discussions many published articles because the answers are not there. I am aware, of course, that it is easy for a subeditor such as myself to change the meaning-I make my suggestions in pencil on the page so that the author or editor can erase them if they disagree with the new meaning.

I look at the grammar in a simple way-checking all verbs for

Department of Pathology, King's College Hospital, London SE5 9RS W F WHIMSTER, MRCP, MRCPATH, senior lecturer
Lastly, if I am engaged in the authors' field of work, I shall want to read their methods carefully and critically. Standard methods may be cited by reference, but new ones or modifications of established ones must be given in enough detail to allow interested persons to repeat them accurately. When I was responsible for honours students, I found it a good exercise for them to try to repeat new methods described in papers relevant to their studies. Almost always, the methods were either incompletely or inaccurately described and could be reproduced only after correspondence with their authors.

\section{Discussion}

Keeping up to date is a responsibility in which doctors often fail their patients. Of course, doctors are busy, but they are bad doctors if they stop reading about their subject. Writers must make their articles readable if they are to be read; and they must realise the competitive nature of their quest for readers. During my active professional life I necessarily read a great deal-at home, in trains and buses, in the laboratory and office; but I never read as much as some applicants for posts claimed that they did. Latterly, I read two weekly journals and two periodicals (I had better not say which) besides many manuscripts, reports, contents lists, abstracts, and reprints. I had to be highly selective, and I proceeded as described in this paper through title, summary, results, discussion, introduction, and review of the literature to methods and material in that order. If it helps writers of papers to have this account of one reader's approach I have reached my objective. their subjects; all pronouns for their nouns; all adjectives and adjectival clauses to see what noun they are telling me more about; all adverbs and adverbial clauses for the verbs they modify; and I examine every dull passive construction to see if it can be made active. I reject circumlocutions, woolly words, abbreviations (most readers cannot remember what they mean), and pomp, unless it is on purpose. The passage which follows shows many common examples of all of these failings, while the succeeding list shows how these infelicities may be improved. One has to be careful not to be carried away by this sort of thing, and it may need more than one attempt.

\section{Introduction}

Approximately 200 grammes of boro-lithium activated charcoal (BLAC) are needed in order to treat each severe case of A phalloides poisoning at the present moment. Ford et al (1975) were of the same opinion but they anticipated that deactivator coated charcoal would be of assistance to a wider spectrum of patients at some future date.

After treatment commences the urine becomes black in colour comparatively frequently and a considerable proportion of patients demonstrate skin rashes due to the fact that $B L A C$ still contains impurities. It may be noted from the literature that during the time the rash lasts the serum charcoal level is elevated in excess of $20 \mathrm{mg} / 100 \mathrm{ml}$. It is also probable that the blood supply to the lower limbs is significantly decreased relative to the upper limbs in females on contraceptive therapy.

In this situation it seemed to the present writers that, as already stated, more sophisticated forms of charcoal therapy could be developed, and they theorised that experiments in which rats were sacrificed following charcoal dialysis would reveal new data about the interactions between charcoal and the new pomp-deactivator, Medipen.

In this communication... 